This PDF is a simplified version of the original article published in Internet Archaeology. Enlarged images and video which support this publication can be found in the original version online. All links also go to the online version.

Please cite this as: May, K. 2020 The Matrix: Connecting Time and Space in archaeological stratigraphic records and archives, Internet Archaeology 55. https://doi.org/10.11141/ia.55.8

\title{
The Matrix: Connecting Time and Space in archaeological stratigraphic records and archives
}

Keith May

\section{Summary}

The records of archaeological stratigraphic data and the relationships between stratigraphic units are fundamental to understanding the overall cohesiveness of the archaeological archive of an excavation. The information about individual units of excavation identified on sites with complex stratigraphy is most often held in the site database records and stratigraphic matrix diagrams, usually documenting relationships based on the laws of stratigraphic superposition and the Harris matrix conventions (Harris 1979). However, once the matrix diagram has been used to record the information during excavation, there is far less consistency in how those stratigraphic records, and any associated phasing information, are finally deposited in the archives. For that valuable data to be successfully identified and re-used (particularly if the rest of the data is in a database), the stratigraphic and phasing data needs to be in a format that can be interrogated as part of the database. In practice, often only a (paper) copy of the matrix diagrams make the archive. This means that the critical temporal and spatiotemporal relationships upon which the phasing of sites is built, cannot usually be interrogated or (re)used without lengthy and wasteful re-keying of that data into another version of the database. 


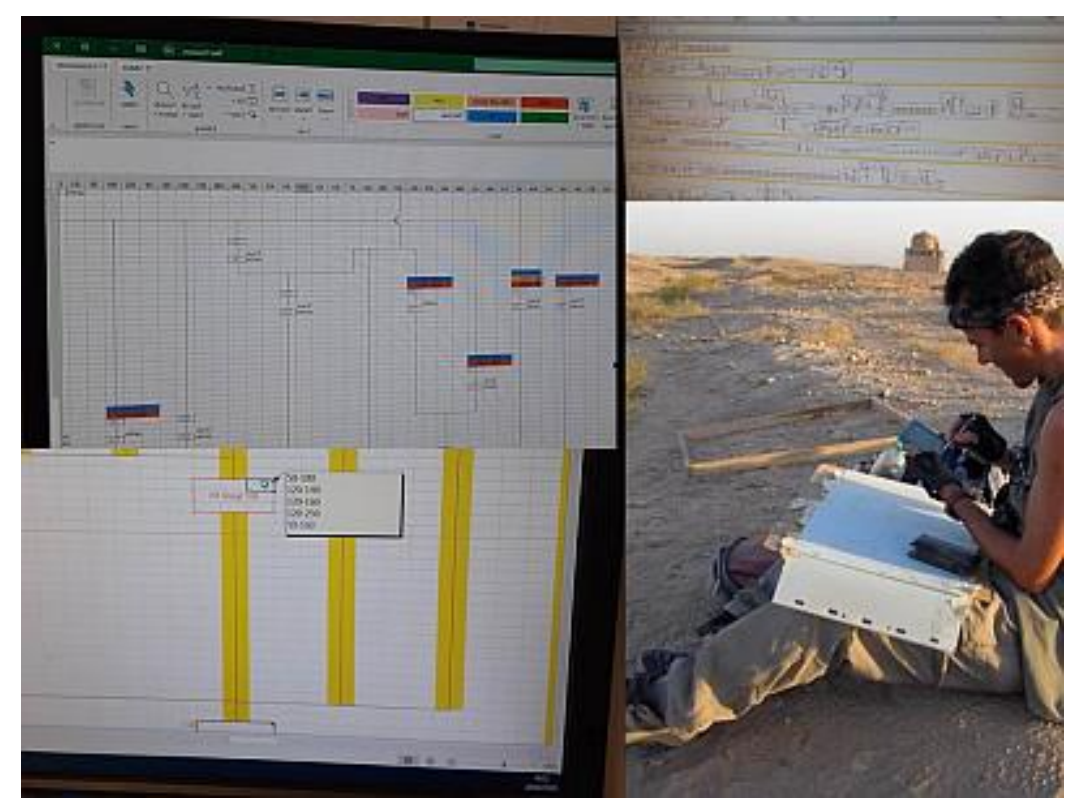

Examples of keeping a 'running matrix' drawing on permatrace and stratigraphic data in a handheld database during fieldwork, and the use and analysis of matrix data during post-excavation

The stratigraphic, sequencing and temporal information held in a matrix is fundamental in further studies of the site records and in working out how the site may relate to other excavated sites of similar or related dates and phases. This article will suggest ways in which the stratigraphic data from excavations and the reasoning processes carried out in subsequent analysis could be better managed, to make matrices (re)useable as part of a more integrated digital archive.

This article examines how conceptual reference modelling, particularly using temporal relationships, can be used to explore these issues and how associated technologies could enable semantically-enriched deductions about the spatio-temporal and purely temporal relationships that fundamentally link archaeological data together. It will also consider where further work is needed both to deal with analysis of spatial or temporal records and to enhance Bayesian chronological modelling and associated temporal reasoning, and how this may form the basis for new linkages between archaeological information across space-time. 


\section{Introduction to Stratigraphic Data and Analysis}

The background for this article is derived from a range of work over the last ten years to consider the conceptual reference modelling of archaeological data, but this contribution focuses in particular on more recently highlighted issues arising from the modelling and re-use of stratigraphic data and associated digital records from excavation archives.

Here I focus on the use of the Harris matrix in the methodology most commonly known as 'Single Context Recording' (Spence 1990). In single context recording we literally remove and record each 'piece of the stratigraphic jigsaw', one piece at a time. Other methodologies for stratigraphic recording do exist, but in 35 years of UK and international fieldwork, I have not encountered any better method to record stratigraphic relationships during excavation than the Harris matrix. One of the most significant aspects of the stratigraphic approach, is that it deals primarily with the relative temporal sequencing of archaeological stratigraphy (i.e. which archaeological strata come before and after each other) but does not require absolute chronological dating of the archaeological stratigraphy itself according to any independent time framework, such as dates AD/BC or BP (although absolute chronological dating of objects contained or associated with stratigraphic levels is an important associated part of stratigraphic modelling. See Section 9.1). This distinction between absolute chronologies and relative chronologies is discussed by Gavin Lucas, who categorises archaeological stratigraphic sequencing, of the type developed by the Harris 'Principles of Stratigraphy', as a primary relative chronology (Lucas 2005, 3).

Experiences derived from the Semantic Technologies for Archaeological

Resources(STAR) project (Tudhope et al. 2011) suggest that semantically interrogating graph database relationships using RDF (Resource Description Framework)-based technologies, incorporating ontological modelling of stratigraphic spatio-temporal relations and more explicit use of broader temporal relationships, could help improve the relative sequencing and phasing process. As a further benefit it could help to provide a basis for a much needed, information-rich, archival structure and digital preservation format.

\section{The Harris Matrix and Stratigraphic Relationships}

The Harris matrix diagram was developed, and is still principally used during excavations, to record the stratigraphic relationships between single units of stratigraphy - referred to as single 'contexts' in many recording systems, particularly in the UK (Spence 1990).

Most commonly, the full matrix record for an excavation is built up from a number of shorter matrix components entered on paper (or increasingly digital) standardised recording sheets, and then a final full site matrix is constructed at the completion of the whole excavation or each excavation season or area. At the same time, plan drawings of each stratigraphic unit are made to provide a spatial record that can be cross-referenced 
(often using GIS) along with the stratigraphic relationships held in the database and on the matrix diagram. The Harris matrix has thus become the de-facto standard method for representing and enabling analysis of the temporal sequencing and inter-relationships between units of stratigraphy (which are, more often than not, totally removed during the process of archaeological excavation. The stratigraphic relationships that are documented as a principal part of the record of the excavation form a fundamental part of the overall site record and underpin the relationships between the site's other recorded individual archaeological components. The stratigraphic matrix, as expressed in a Harris matrix diagram, indicates the fundamental structure - the integral stratigraphic 'skeleton' of the archaeological deposits that go together to make the 'site'.

In setting out the fundamental principles of the stratigraphic approach Harris says:

'The matrix system admits to only three possible relationships between two given units of stratification... (A) The units have no direct stratigraphic connection; (B) they are in superposition; and (C) the units are correlated as parts of a once-whole deposit or feature interface' (Harris 1989, 36). 


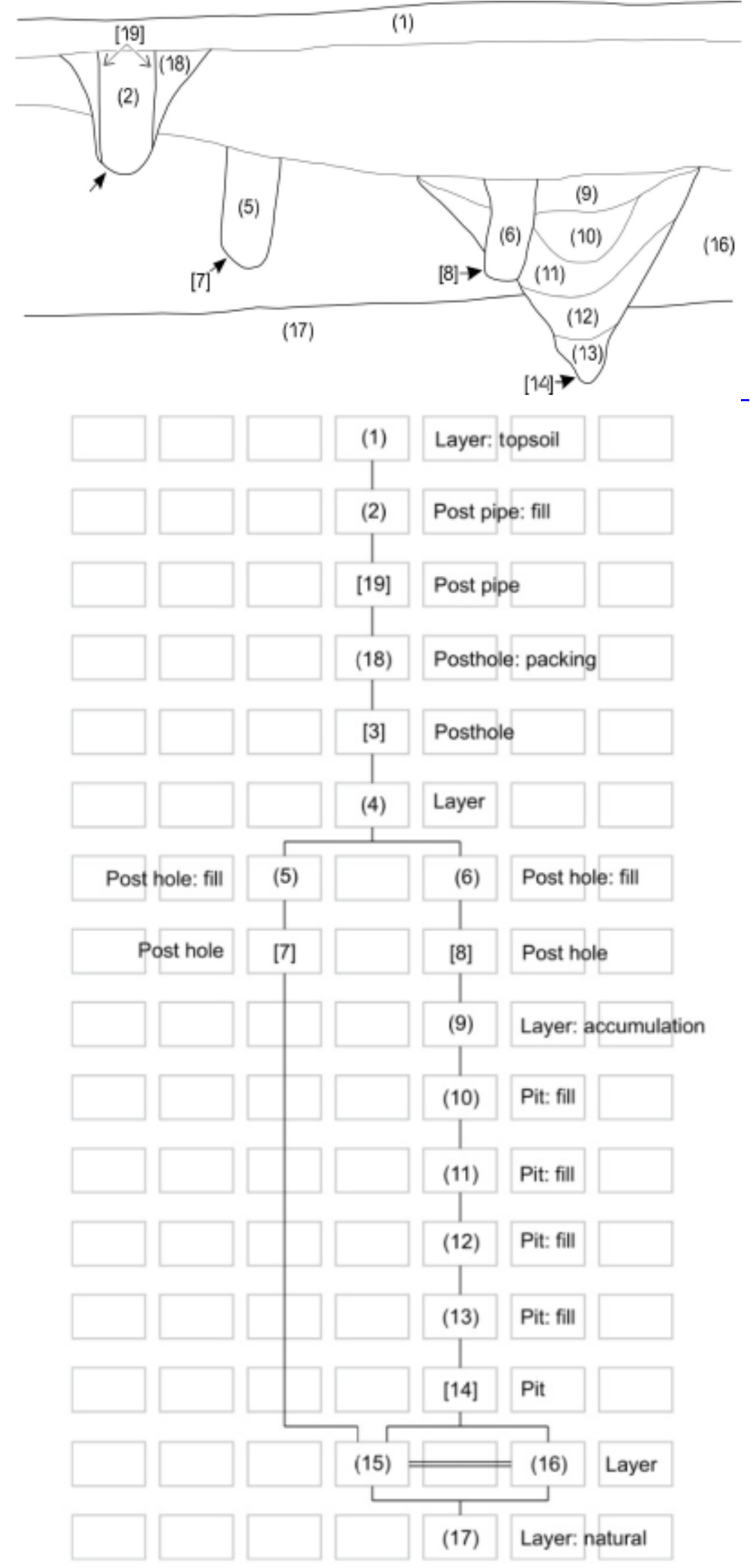

Figure 1a/Figure 1b: Section drawing with example of a Harris matrix from Historic England recording manual (2006) 
The stratigraphic principles upon which the Harris matrix is based are still relevant beyond the excavation process, and often the representation of the stratigraphic relationships in diagrammatic form is invaluable in the analysis processes after excavation has been completed, as Roskams sets out (2001, chapter 13). As part of that stratigraphic analysis process, there are additional relationships, such as the temporal overlap between different stratigraphic groups or features on different strands of a stratigraphic matrix that are identified or interpreted. These may not be so easily, or systematically, represented using just the Harris matrix diagram. This is something Roskams recognises by suggesting various amendments, modifications and different shapes for stratigraphic units in the basic Harris matrix diagrams, and especially to indicate differences in the strength of correlation between groups and features on different strands of the matrix (2001, 262).

What may be thrown into question from this practical need for enhancements in postexcavation is whether the Harris matrix diagram, which focuses wholly on the fundamental spatio-temporal stratigraphic relationships in a purely diagrammatic imagebased representation, is entirely suitable as the only or even the most comprehensive method for preserving all the complex chains of temporal relationships that hold between the individual units of stratigraphy, especially those that are only understood after incorporation of other data during analysis.

Given that the Harris matrix is the most commonly used method to record stratigraphic data during excavation as part of a single context recording methodology, this article will go on to consider if more could be done to build on the Harris matrix methodology and develop additional methods and tools for stratigraphic analysis and stratigraphic archiving, in a way that uses more 'clarity in defining concepts' (Roskams 2001, 279).

\subsection{Review of Carver relationships}

Although the Harris matrix is the best known and has become a standard for single context recording of stratigraphic sequences, particularly for excavations in urban centres with their deep deposits and more extensive archaeologies, other methodologies have been proposed and used to record the sequence of stratigraphic relationships between both contexts (sometimes referred to as Stratigraphic Units) and between groups of contexts and features.

Around the same time that single context recording using the Harris matrix was developing in Winchester and then London in the 1980s, Martin Carver, working in York, was using a sequence diagram (Carver 2009 , 278) that was more concerned with representing the relationships between groups of contexts, described as archaeological features. Carver's approach to such sequence diagrams can be particularly useful to represent aspects of longevity and continuity (or potentially lack of continuity) in the sequences of contexts and features. This representation of how stratigraphic contexts have 'occurred during' the broader interpreted events that are characterised as overall phases, or periods, of a site, is something that perhaps recognises the potential to introduce other temporal operators in the archaeological record (see Section 4).

Carver also makes a fair point that Harris matrices work most effectively for clearly stratified archaeological sites. On more dispersed sites, often in more rural settings, the stratigraphy may be less delineated or inter-connected, and we may need to introduce data from artefact analysis or other scientific dating techniques such as radiocarbon 
dating to clarify the overall sequence of activities. In the case of less clearly stratified sequences, having a more comprehensive way of expressing the differing temporal relationships between those contexts and groups of features that are recognised, may still be important to show the relative temporal relations, and continuity, between recorded strata.

Much of Carver's sequencing builds upon the information introduced during the 'postexcavation' analysis stage of archaeological work. This is in contrast to the Harris matrix, which is developed primarily as a field recording technique during excavation, but which then gets adapted or enhanced, in some cases, for further stages of analysis work.

Is there necessarily a need for this division in the process of stratigraphic reasoning from excavation to post-excavation? The pragmatics of on-site recording constraints tend to lead to a minimal as possible approach to initial recording of stratigraphic relationships. But could there be value (and efficiencies) in having stratigraphic sequencing methods and tools that enable the work on the stratigraphic sequencing, grouping and phasing to be more integrated from excavation records throughout analysis work? This might require development of new tools for stratigraphic analysis that could better support both recording and the efficient processing of the grouping and phasing analyses, along with the incorporation of the temporal reasoning and better representation of the interfacial information that lies implicit in the context level records.

\section{Harris Matrices and 4D Spatio- temporal Relationships}

Harris (1989) acknowledges that the matrix is designed to represent four dimensions in the archaeology it records. When he refers to the 'stratigraphic sequence' in the following he is talking about the stratigraphic matrix diagram (bold emphasis mine).

'A stratigraphic sequence is a diagram of relative time: it shows all four dimensions of the stratigraphic accumulation of a site, unlike the two-dimensional image of the physical world of stratified deposits seen in a section' (Harris et al. 1993, 18). 


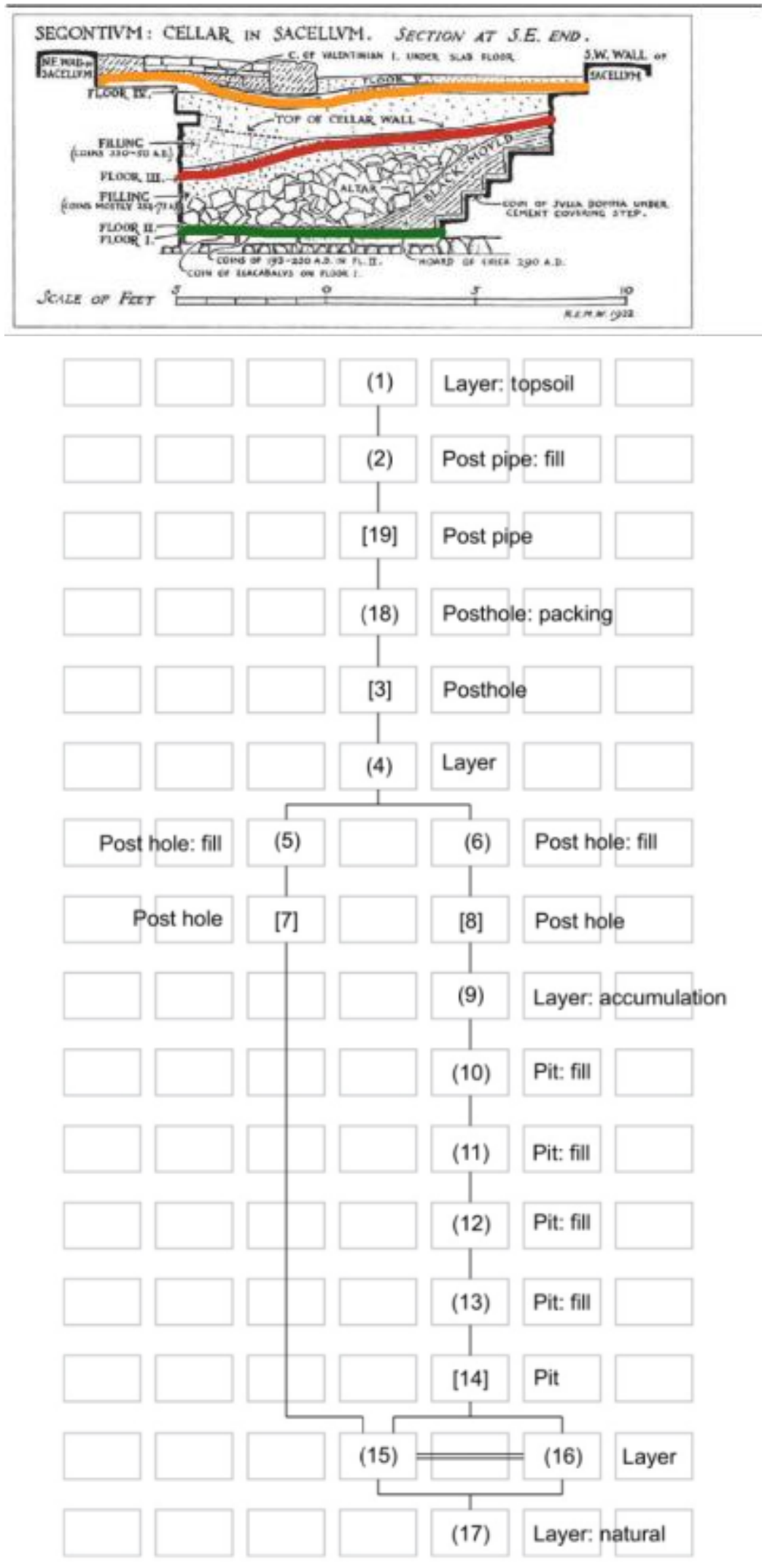

Figure 2: Drawing by Mortimer Wheeler of a section across the cellar in Sacellum at Segontium, with added colours highlighting different 4D floor phases in contrast to Harris Matrix diagram boxes, in contrast to Harris Matrix boxes (Figure 1b) 
One can appreciate the main sentiment in this statement, that the matrix is designed to represent the temporal sequence of stratigraphic units, as well as the physical (3D) juxtaposition of those stratigraphic units - temporal and spatial. As such, Harris regards the matrix as a diagram to represent both the spatial relationships of stratigraphic units that sit next to each other in the sequence, and most crucially also their direct relative temporal sequence i.e. which stratigraphic units come directly before or directly after one another temporally in the surviving archaeological strata. Harris $(\underline{1989}, 111)$ describes this in the following passage:

'the stratigraphic sequence on most archaeological sites cannot be directly equated with the physical order of stratification, as shown in sections. Those physical relationships must be translated into abstract sequential relationships'

For archaeologists, an equally crucial question may be the degree to which the Harris Matrix can fully represent all four dimensions as the fullest record of the archaeological stratigraphy of an archaeological investigation. It is open to question whether the matrix diagram actually represents that sequence better to anyone other than fellow archaeologists. For non-archaeologists, a well-labelled section drawing will actually convey the general notion of a sequence of layers better than a matrix, although that is not really the point Harris is making, but it may reflect a need to consider different choices for presenting the stratigraphic information to varying audiences. Archaeologists use a range of other records alongside the matrix to represent and analyse the spatial relationships between stratigraphic units, such as drawn plans and, increasingly, the spatial components of the site represented in a GIS.

It is not that the matrix expresses the spatial relationships between units better than a detailed section drawing or the overlay of spatial plans, but it does express the excavators' understanding of the 4D spatio-temporal sequence by which contexts were deposited, and most significantly therefore the physical and temporal sequence in which they were excavated, based on the excavators stratigraphic reasoning. l'd suggest this is what Harris recognises in the phrase 'a stratigraphic sequence ... shows all four dimensions of the stratigraphic accumulation of a site'.

When excavating a complex sequence of stratigraphic units, we interpret and record the relationships of these units by examination and interpretation of their physical positions and relations to each other in the ground (literally 'in context'), how they fit with each other and their relative associations among the surrounding stratigraphy. A stratigraphic unit does not express its place in the temporal sequence by any characteristics that are independent of its physical juxtaposition to other surrounding stratigraphic units. As such, I would argue the stratigraphic relationship is a wholly spatio-temporal relationship that cannot truly be decided without some recourse to both the physical positioning and temporal ordering of the stratigraphic units being examined. The temporal position of stratigraphic units in the stratigraphic sequence is inferred from the physical and spatial juxtaposition between the units that is identified during excavation (and a fundamental assumption that the so-called 'arrow of time' is always unidirectional). This is also expressed by Harris in his Law of Stratigraphical Succession.

'A unit of archaeological stratification takes its place in the stratigraphic sequence of a site from its position between the under most (or earliest) of the units which lie above it and the uppermost (or latest) of all the units which lie below it and with which the unit 
has a physical contact, all other superpositional relationships being redundant' (Harris $\underline{1989}$, 34).

The mention of 'with which the unit has a physical contact' is significant here in stipulating the spatial requirement along with the earliest/latest parameters for the temporal dimension.

For archaeological records, we need the precise meaning of 'stratigraphically before' and 'stratigraphically after' to represent the physical juxtaposition that goes along with the inferred temporal relationship. These laws of stratigraphic sequencing of course also hold just as true for the recording of standing structures and buildings above ground (along with other spatio-temporal phenomena, Vandevelde et al. 2018) as they do for buried archaeological deposits.

\subsection{Stratigraphic analysis - use of the matrix for phasing (or periodisation)}

Having divided the archaeology during excavation into various units for recording purposes, we use stratigraphy, and associated temporal logical relationships between the physical materials recorded, as the 'reasoning glue', in the form of Phases and Periods, thus connecting all these different spatial and temporal phenomena together with narratives, site biographies and syntheses, to explain our conclusions.

The terms Phase and Period are defined variously and sometimes interchangeably by archaeologists. For Harris, it seems a Phase groups contexts of similar age, and a Period groups phases of similar age, thus yielding a nested series of time intervals (Harris 1989, 158). As Dye and Buck observe,

'Defined in this way, both phases and periods are interpretive constructs that are typically formulated with both stratigraphic and non-stratigraphic information. Because "phase" is also used to describe Bayesian chronological models, here we use the term "stratigraphic phase" to refer to a group of contexts, and the term "chronological phase" to refer to a time period in a chronological model' (Dye and Buck 2015, 87).

Harris matrices, particularly when used as part of the phasing process, may represent more than just a single sequence of temporal relationships. Parallel multi-linear strands in a matrix, which may not be part of the same stratigraphic sequence, nevertheless are related by being represented in the same temporal phase and at broadly equivalent horizontal levels on the matrix diagram. In the process of phasing, other implicit temporal relationships that hold between stratigraphic units may be incorporated into the layout of the matrix diagram, without being explicitly recorded anywhere else in the dataset represented by the diagram. Examples of such temporal relationships and reasoning used during the process of correlating groups of contexts into the same phases across different strands of a matrix are 'overlaps in time with these other stratigraphic units', or 'occurs during the same phase as these other stratigraphic units'. These temporal relationships, as used in the phasing process, are purely temporal relations and are not derived from the spatio-temporal juxtaposition of what we record in the ground, although the contexts at the start and end of a phase will sit within the stratigraphic sequences of the matrix and hold Before/After relationships to other contexts. 
Moreover, the phases in matrix diagrams are, by nature, usually designed to represent continuous blocks of time. Thus, the end of one phase meets in time with the beginning of another phase. If there is indication of truncation representing a chronological hiatus then this could be represented as a phase or period in its own right in a matrix diagram, and would still hold a temporal relationship (possibly of less certain duration) to other phases. Roskams describes the key components of the phasing process as the grouping of stratigraphic units (actions) into blocks (activity groups), and the grouping of activities that occur across the whole site into 'periods' (site-wide periods).

'I would wish to recommend that, where one can identify broad patterns of activity which cross the whole site, this should be explicitly acknowledged in the phasing structure. Hence for present purposes, being "site wide" defines a "period". Knowing that such a period exists in analysis requires that a line can be drawn across the full width of the sequence and there is an argument for every unit on the site, whether related to its specific characteristics or more general considerations, lies above that line. Thus no unit can belong to more than one period and, if one period can be successfully and usefully created, then every unit will belong either to it or to another period which, by definition, precedes or follows it' (Roskams 2001, 260).

To explain this visually I have included (Figure 3) an amended version of Roskams' own figure (Roskams 2001, fig. 31) to show that his 'sub-periods' represent the overlaps in time relationship and his 'periods' represent occurs during and meets in time relationships. Figure 3 is explicitly annotated to express respective temporal operators. 


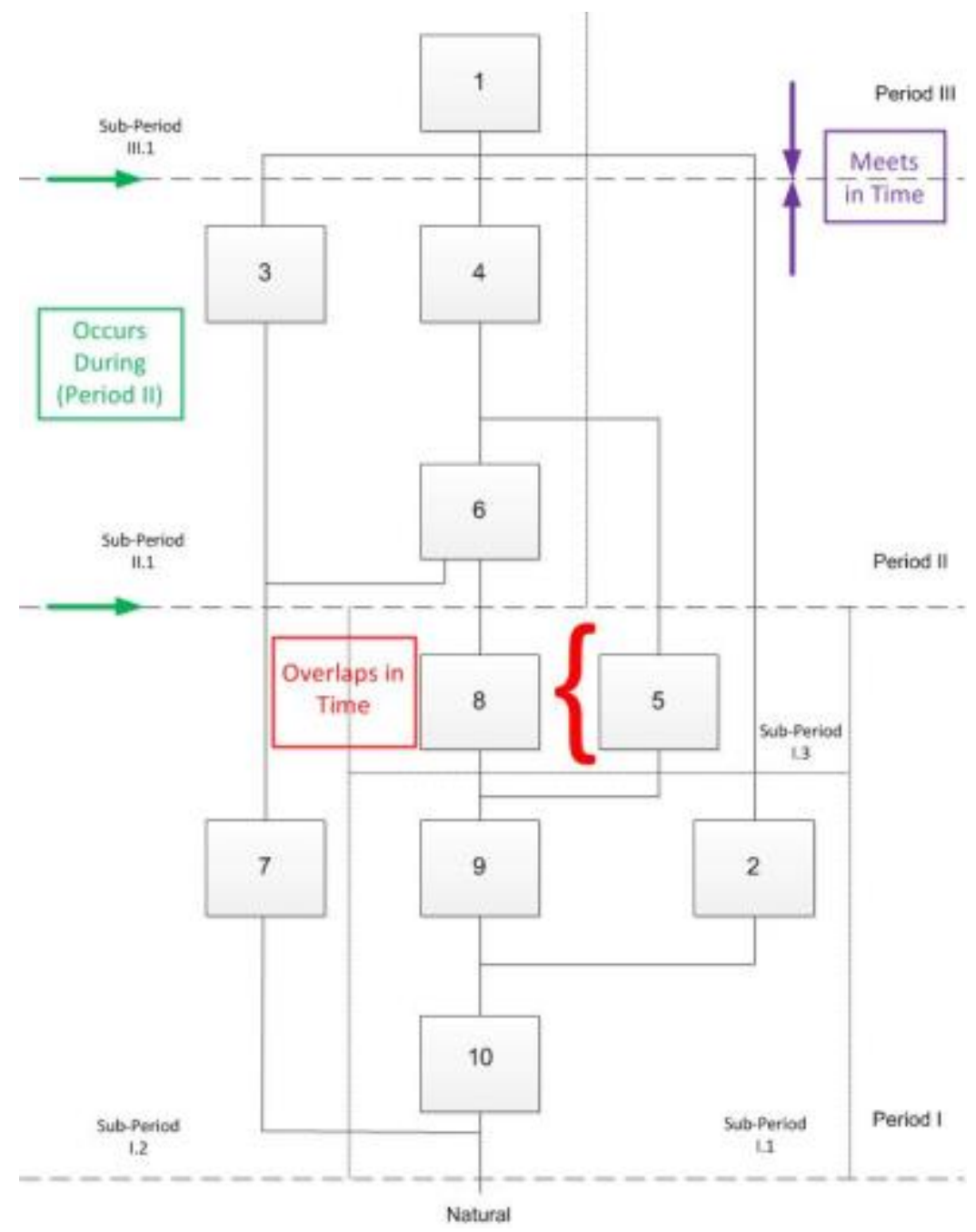

Figure 3: Example matrix annotated to show how Roskams' 'sub-periods' represent the overlaps in time relationship and Roskams' 'periods' represent occurs during and meets in time relationships. (After Roskams 2001, fig. 31)

These additional temporal relationships, however, currently only seem to be used implicitly in the processes of stratigraphic analysis and, crucially for the re-usability of the resulting digital archive, often appear only within diagrammatic representations on paper rather than recorded more formally or explicitly alongside the fundamental stratigraphic (spatio-temporal) relations in the database. These additional temporal relationships have been previously well described by Allen (1983). I will now look at how these additional temporal relationships fit with the existing Harris matrix relationships of before, after and correlates and how the more explicit expression of them in our stratigraphic analysis may enable enhanced interpretation and increased functionality in the use of matrix diagrams and stratigraphic records in archives. 


\section{Allen Operators for Temporal Relations}

J.F. Allen identified a set of 13 operators that define each of the possible temporal relationships for any pair of known relative temporal entities (such as two stratigraphic units) in a temporal sequence (Allen 1983). These are relative temporal operators, so no absolute dating sequences or dating timespans are implied or required for their use.

The operators work logically in pairs such that one temporal relationship has a direct inverse relationship. Hence if event $A$ happens Before event $B$ then logically (a priori) event B must happen After event A. Likewise if event A occurs During event B then logically event B must Contain event A. The set of 13 operators are shown in Figure 4.

Figure 4: Allen temporal operators showing pairings of temporal relationships

Relation

\begin{tabular}{|c|c|c|c|}
\hline Before (precedes) & $\mathrm{b}$ & After (preceded by) & bi \\
\hline Meets & $\mathrm{m}$ & Met by & $\mathrm{mi}$ \\
\hline Overlaps & 0 & Overlapped by & oi \\
\hline During & $d$ & Contains & di \\
\hline Starts & $\mathrm{s}$ & Started by & si \\
\hline Finishes & $f$ & Finished by & $\mathrm{fi}$ \\
\hline Equals & $=$ & & \\
\hline
\end{tabular}

One crucial aspect of these operators is that they comprehensively describe the set of possible temporal relationships between any pair of definite temporal intervals. In this sense the operators are exhaustive of the range of temporal relations, in that any pair of definite temporal intervals can be described using one of the relations. For example, take a simple example of Nelson Mandela's birthdate and the date of the first moon landing.

Nelson Mandela was born Before the date of the first moon landing; the date of the first moon landing was After Nelson Mandela's birthdate. The date of the first moon landing was During Nelson Mandela's lifespan; Nelson Mandela's lifespan Contains the first moon landing. While the written expression of these relationships may be a little 'clunky', the semantics of the temporal reasoning should be relatively straightforward. If Nelson Mandela's birthdate is Before the moon landing, then his birthdate cannot be During the first moon landing. Also there is a distinct scope for these operators in that no two definite temporal intervals can be related by more than one of the relationships (although obviously the inverse relationship does hold). To continue the example, Nelson Mandela was born Before the first moon landing and therefore his birthdate cannot be after, or during, overlapped, equal in time to, or meeting with the date of the first moon landing. 
A key point here with particular regard to stratigraphic relationships is the distinction between the paired relations of Before/After and Meets/Met by in Time. The notion of Before/After is used to sequence stratigraphic units, so that one unit comes directly before or after another in the archaeological sequence (i.e. no other units of stratigraphy were recorded between them). But this does not imply that those units in the sequence meet directly with each other in time. Indeed Harris and others (Clark 2000a, 103) are keen to underline the importance of interfaces as representing temporal intervals between stratigraphic units and discuss the fact that surfaces of stratigraphic units may have remained 'open' and in use for considerable periods before the next deposit of soil was made, or cut feature dug, to provide the next stratigraphic unit (see also Section 8.5).

The Allen temporal relationships are also qualitative, meaning that they express temporal relationships that are relative to each other without reference to any absolute dating framework. As Gavin Lucas summarises, 'a relative chronology is one based on the inter-dependence of the data being studied - this can be anything from stratigraphy to periodization. Here, the chronology of the data is solely expressed relative to other data' (Lucas 2005, 3). With Allen relationships no actual absolute dates are required in order to use the Allen operators for temporal reasoning, although obviously with stratigraphic sequences absolute dating evidence or more specific timespans can be incorporated, such as where an excavated object with an attributed date (e.g. a coin or inscription) is associated with the date for the event of the deposition of a stratigraphic unit.

\section{Temporal Granularity}

Temporal granularity refers to the idea that there can be different resolutions of scale for time depending upon the scale of measurement i.e. we can talk about time as a matter of days, or days within weeks, or then days and weeks within years, decades or centuries. At each different measure, the temporal resolution changes e.g. from a few days to a few centuries. An analogy might be how, in a GIS, one can zoom in or out on the spatial resolution of a map to look at something in plan view either at 1:10, or 1:1000. So a group of days will occur during a year, and likewise the same days and year will occur during a certain decade or century. This is a relative hierarchical relationship that can cover any particular temporal sequence. The archaeological grouping and phasing processes make use of this relative hierarchical temporal granularity.

\subsection{Temporal granularity in stratigraphic analysis}

The temporal relationships for archaeological stratigraphic units are not just sequential but they can have nested relationships to other temporal timespans within the overall stratigraphic matrix. The relative temporal relationships set out by Allen (1983) enable us to be more explicit about the temporal scales, or resolution, in our data. Rather than just providing the sequence of stratigraphic units, we can also express that different sequences occur during larger proportions of time (timescales). So as well as noting that a single context forms part of a larger group of contexts, we can identify that several 
groups all occur during a similar timespan and therefore we are prepared to say they occur during the same 'Phase'.

Phasing is still partly about sequencing; hence we usually give the phases in our phasing sequences consecutive numbers, but the more significant temporal relationship is the association with a broadly similar temporal scale of resolution - namely associating groups of contexts within the same phase. A similar nesting process occurs with placing phases within temporal periods. This will usually be informed by the analysis of the key dating evidence from finds associated with the stratigraphic units within such phases. These might be fixed dates on objects such as coins, or other 'spot-dates' that often give more specific terminus post quem (TPQ) or terminus ante quem (TAQ) dates, or the more interpretative dates from stylistic analysis of ceramic, or similar finds, assemblages. Otherwise there may be absolute dating evidence provided by dates of samples sent for scientific dating such as radiocarbon or dendrochronological dating.

'Commonly, then, archaeologists obtain radiocarbon determinations from samples associated with specific excavated features. On the basis of such determinations, the types of questions posed include "when did event $A$ occur?", "what is the time period between event $A$ and event $B$ ?", "what is the likely order of events $C, D, E$ " and so on' (Buck et al. 1996, 215).

As Niccolucci and Herman acknowledge 'dating often implies coarsening the time granularity to make time-span assignments feasible, or adopting approximations' (Niccolucci and Herman 2015, 259).

\section{Examples of Current Practice in the use of Matrices as Records of Stratigraphic Analysis}

To show how the additional Allen relationships have already been used implicitly in archaeological recording, I will provide a number of examples, highlight some associated issues, and suggest some possible opportunities to enhance stratigraphic recording and analysis practices.

\subsection{Silbury Hill digital archive}

Figure 5 from the Silbury Hill archive (English Heritage 2014) with additional illustrative annotations of the Allen operators, shows a relatively good level of archive practice for the deposition of stratigraphic records. The main database tables are deposited in a Comma Separated Value format (CSV) that can be opened in spreadsheet software such as Excel. For Silbury, the CSV data records which contexts were attributed to which phases in the final analysis, along with a version of the Harris matrix in an Excel spreadsheet format. The advantages of this is that the overall matrix is easily viewable but, most significantly, the data in the CSV format is more re-useable than it would otherwise be if only in the diagrammatic format. 
Having the data in CSV format does at least make it possible to re-use the information in a way that reflects which individual stratigraphic units are within each phase. However, in this particular case, the actual stratigraphic relationships (above/below/contiguous) between the individual contexts is recorded in the site database (not just shown on the diagrammatic version) so reasoning over those stratigraphic relationships would be possible if it is included in the final site archive.

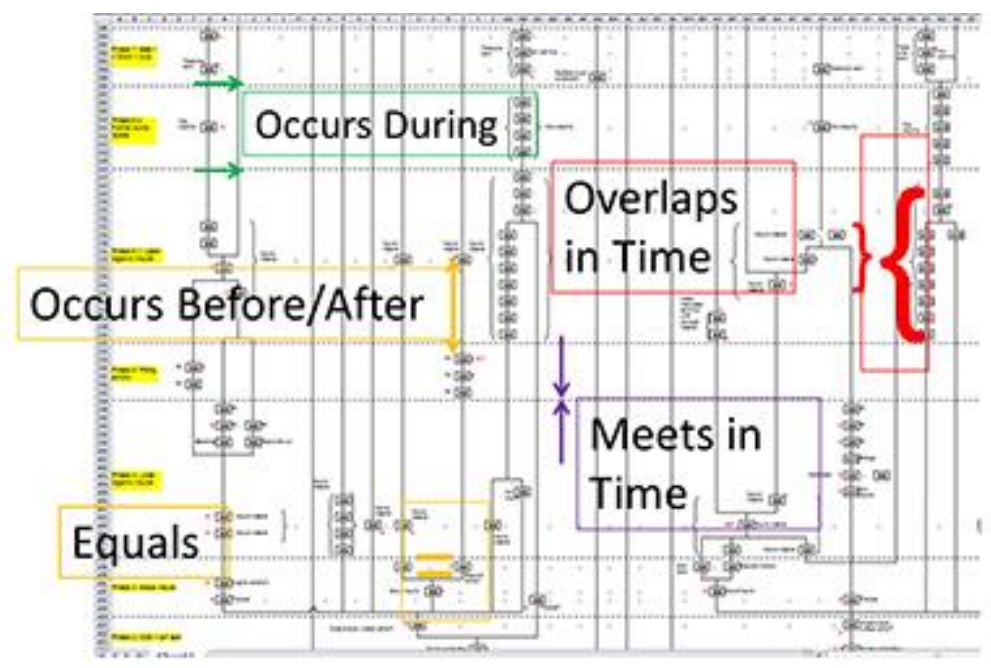

Figure 5: Silbury Hill - stratigraphic matrix archive with annotations to highlight implicit Allen relationships. Silbury Matrix, The site Harris matrix in English Heritage $\underline{2014}$. Video with audio explainer (transcript)

\subsection{Landscape Research Centre matrix}

In the case of the Landscape Research Centre (LRC) matrix diagram (Powlesland and May $\underline{2010}, \underline{5.4})$, the data are entered into an Excel format to enable a link to be made from the matrix to the Gsys geographic data management system (GIS). This allows the related plans of the contexts to be accessed using the 'Matrix Manager' software within Gsys to 'drive' the GIS display of associated spatial data, to generate plans that show a specific sequence of stratigraphic units or a phase plan for publication. The stratigraphic relationship between individual contexts is also documented in the database (spreadsheet) in tabular format, recording which contexts are stratigraphically below (strat_below which implies the inverse relationship of stratigraphically above) and which are strat_equal, thus better enabling re-use of the stratigraphic relationships (above/below/contiguous) in the dataset. 


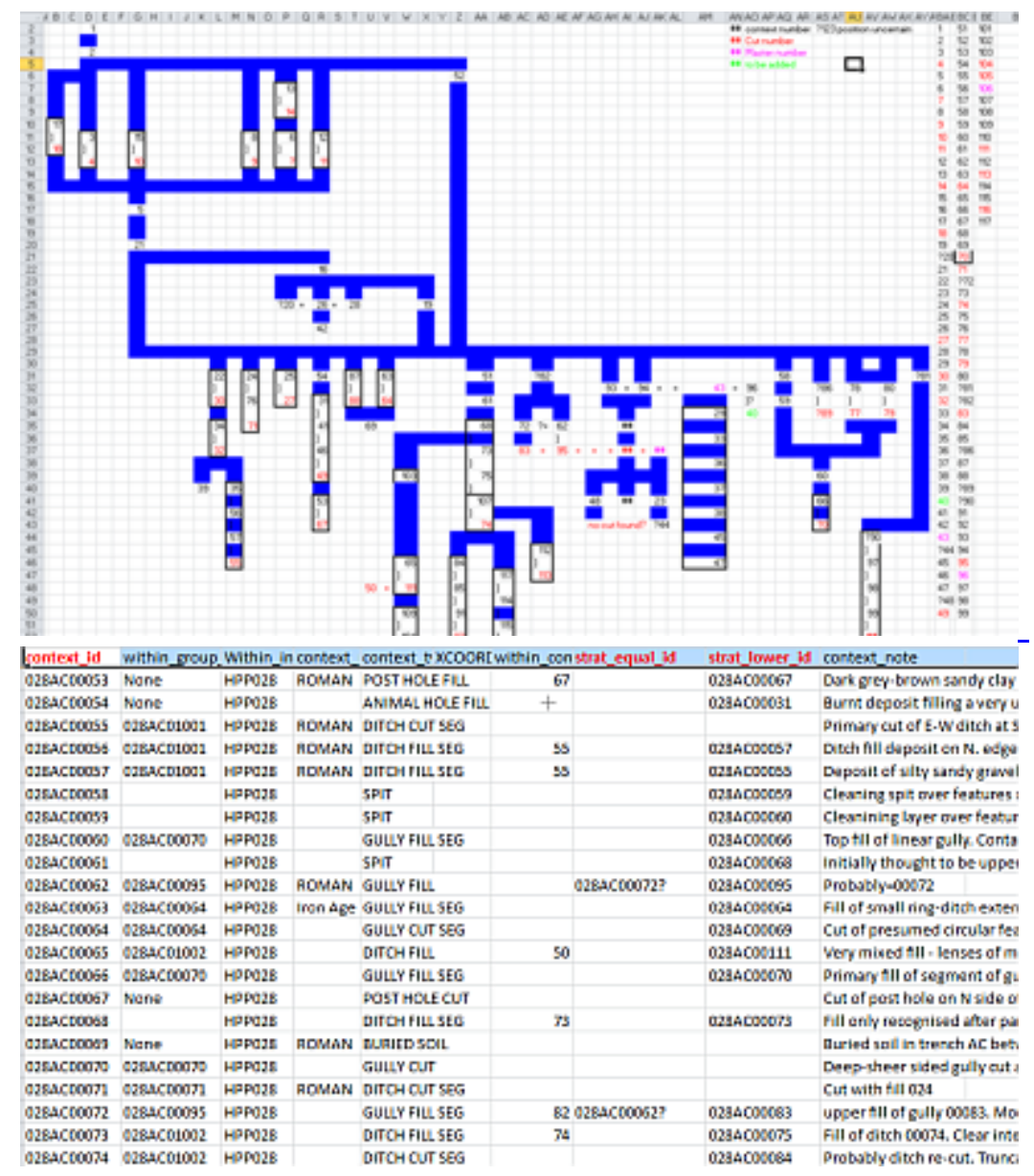

Figure 6a/Figure 6b: Landscape Research Centre matrix diagram and spreadsheet

\subsection{Stratigraphic analysis and the 'Phasing Index'}

Although the Harris matrix has become the de facto standard used for recording stratigraphy during excavation and after, there is generally a much less systematic approach to what happens in the stratigraphic analysis carried out on those stratigraphic records in order to produce the resulting publication texts and outputs.

Harris says, 'The division of the stratigraphic sequence into phases or periods may take place during the course of the excavation, but it is subject to change depending upon the analysis of the artefacts. The layers and interfaces are grouped according to their stratigraphic positions in blocks called "phases" .... If there are no structural markers, such as a building level or the cutting of a ditch, the division of the stratigraphic sequence into phases may have to await the results of the analysis of artefacts and datable remains' (Harris 1979, 115). A useful illustration of the nature of phasing (or periodization as Harris labels it) is given by Harris (1979, fig. 25) (reproduced here as Figure 7). 


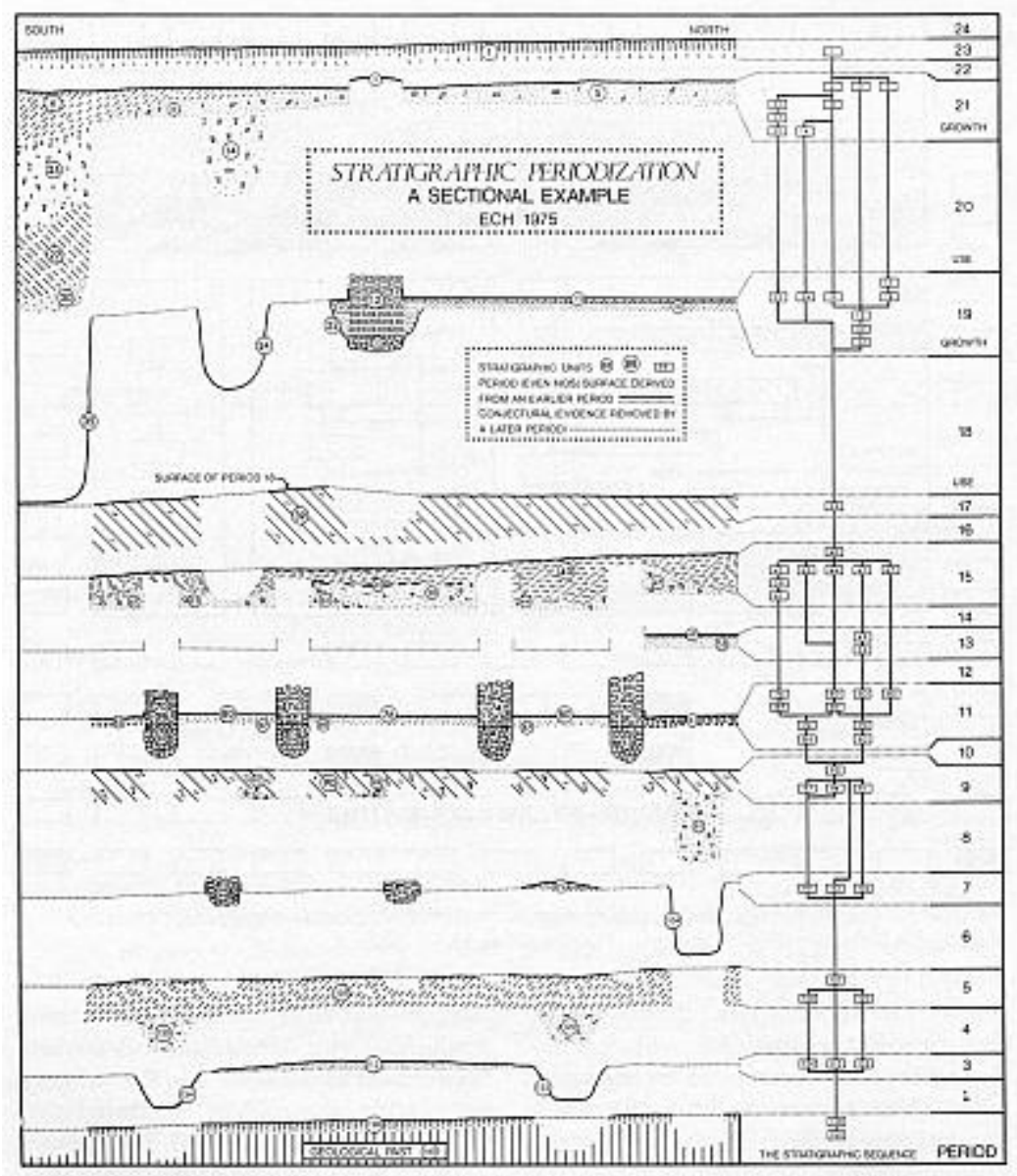

Figure 7: Harris 1989, figure 25. In this illustration, a section has been split into 24 periods. The odd numbers are depositional periods and the even numbers are interfacial periods. Depositional periods are represented best by section drawings; the interfacial periods by plans (Harris $\underline{1979}$ )

The complexity of the analysis and the scale of analysis outputs will reflect the degree of complexity in the archaeology encountered on any site (Shepherd 1993). However, in outline, a typical approach to stratigraphic analysis is to identify any groups of stratigraphic units that go together to represent distinguishable activities at separate phases of time during the archaeological duration of the site. Given the ambiguities that can arise in terminologies used to describe stratigraphic analysis processes

(Clark 2000b), for the purposes of this article, I will set out and use the following concepts:

\section{Sub-Group (context series)}

A number of contexts with close stratigraphic links that are interpreted as forming a single 'activity'. The stratigraphic units in a sub-group will all be on the same stratigraphic sequence in the matrix. Usually a sub-group will be characterised by one of three processes: construction, use or disuse. A typical example of a subgroup would be the stratigraphic units of a posthole with its primary fill(s). 


\section{Group (context group)}

A group is usually a more interpretative entity than a sub-group, and is a collection of stratigraphic units that are interpreted as being grouped together to form a series of inter-related activities (most often a group of sub-groups), such as the make-up and levelling deposits and construction of a new room in a building or a group of postholes interpreted as a single structure. The aim in labelling and numbering groups in the stratigraphic matrix is to identify and enable discussion points to be written as part of the overall site narrative. For complex stratigraphy with many groups, a separate Group matrix diagram may also be produced that simply shows the groups without individual stratigraphic units as an aid for writing up inter-group discussion texts.

Phase

A phase is usually characterised by having a designated duration or timespan with an allocated, but not necessarily absolute, start date and end date.

Demarcating a phase on a stratigraphic sequence brings together the various groups of structures, deposits or other features in the archaeology that are interpreted as contemporary or that fall within the timespan designated by the start and end dates of the phase. A phase is usually identified as being across the whole of a site, but on occasions 'sub-phases' may be identified that apply to just a particular group of contexts. The timespan of a sub-phase will necessarily be 'During' the date range of any over-arching 'main, or site wide, phase'.

The phasing process for a multi-phase stratigraphic sequence will usually include the annotation of the site matrix diagram with phase numbers and incorporation of horizontal banding (or boxing) of the matrix diagram to represent the different phasing 'levels'. An example of this approach can be seen in the Silbury Hill matrix (Figure 5, phases are highlighted in yellow).

As part of keeping track of the relationships (between individual contexts and the succession of sub-groups, groups, or phases that they are allocated to in stratigraphic analysis), a series of cross-referencing tables are usually created. In some organisations these may be included as part of a structured database or, in other cases, individuals may generate separate spreadsheets for this information as they work through the postexcavation stage towards publication. Ideally, if any dated finds (i.e. finds that have associated dating evidence such as coins or diagnostic pottery forms etc.) have been used to incorporate a stratigraphic unit in a certain phase, then that data should be included in any records of the phasing. Such tables of phased records are commonly referred to as the 'Phasing Index' (or sometimes 'Interpretive Phasing Index'), but the formal use of these is by no means standard practice and the evidence from archives suggests these are rarely deposited in a digital archive in any standardised manner.

Unfortunately, therefore, although a similar process is commonly followed, the actual digital outputs of what is archived from such analysis is not consistent. This makes it extremely difficult (or at best a heavy burden) to try and reconstruct this interpretative phasing process from the resulting archives (see Roskams 2001, and below). 


\subsection{Roskams on stratigraphic analysis}

In the final chapter on 'stratigraphic analysis' in his instrumental publication on Excavation, Roskams particularly notes the degree of variation within the process of stratigraphic data analysis in contrast to excavation recording.

'Turning next to data manipulation after excavation, there is a great need to sort out the concepts used in stratigraphic analysis - a glance at chapter 13 shows just how far we have to go here in order to match the systematization which has been developed in the production of the site record. For the most part what is needed is intellectual clarity in defining concepts and then labelling them' (Roskams 2001, 278).

This variability in records creates problems and confusion with regard to developing common approaches to integrating and publishing the stratigraphic analysis. In addition, the problems are exacerbated by the lack of standardised stratigraphic records deposited in archives, and in particular results in problems for re-use of stratigraphic data for analysis using Bayesian dating programmes (Dye and Buck 2015).

The following section aims to show where the use of the Allen temporal operators and related work on conceptual reference modelling may help deal with some of the issues noted above, at least in improving interoperability of the differing semantics used in the records.

\section{Allen Temporal Operators and Stratigraphic Relations used in Conceptual Modelling}

The Allen operators (Figure 8) have been incorporated in the CIDOC CRM ontology (ISO 21127:2006) for the representation of relative timespans associated with recording cultural heritage events (Doerr et al. 2011). The CRM has been extended more recently to enable the representation of archaeological data in the form of the CRMarchaeo extension to the core CIDOC-CRM model (CRMarchaeo) (Doerr et al. 2018). 


\begin{tabular}{|l|c|c|}
\hline Allen operator & Expression in English \\
\hline $\begin{array}{l}\text { A b B } \\
\text { B bi A }\end{array}$ & $\begin{array}{c}\text { A occurs before B } \\
\text { Boccurs after A }\end{array}$ \\
\hline $\begin{array}{l}\text { A m B } \\
\text { B mi A }\end{array}$ & $\begin{array}{c}\text { A meets in time with B } \\
\text { B is met in time by A }\end{array}$ \\
\hline $\begin{array}{l}\text { A B B } \\
\text { B oi A }\end{array}$ & $\begin{array}{c}\text { A overlaps in time with B } \\
\text { B is overlapped in time by A }\end{array}$ \\
\hline $\begin{array}{l}\text { A s B } \\
\text { B si A }\end{array}$ & A starts B \\
\hline A d B & B is started by A \\
B di A & A is during B \\
\hline A f B contains A & A finishes B \\
\hline B fi A & B is finished by A \\
\hline A B B & A takes place at the same \\
& time as B & B \\
\hline
\end{tabular}

Figure 8: Allen temporal operators - see also Figure 5 for use in matrix diagram

Initial work developed the CRM-EH ontological model to enable interoperability of archaeological information recorded using single context recording systems (Cripps et al. 2004). This extension of CIDOC-CRM incorporated the Allen operators as temporal relationships between the three separate entities of Context, Group and Phase recording events and demonstrated how the CIDOC-CRM can be used to map the process by which stratigraphic data is grouped. 


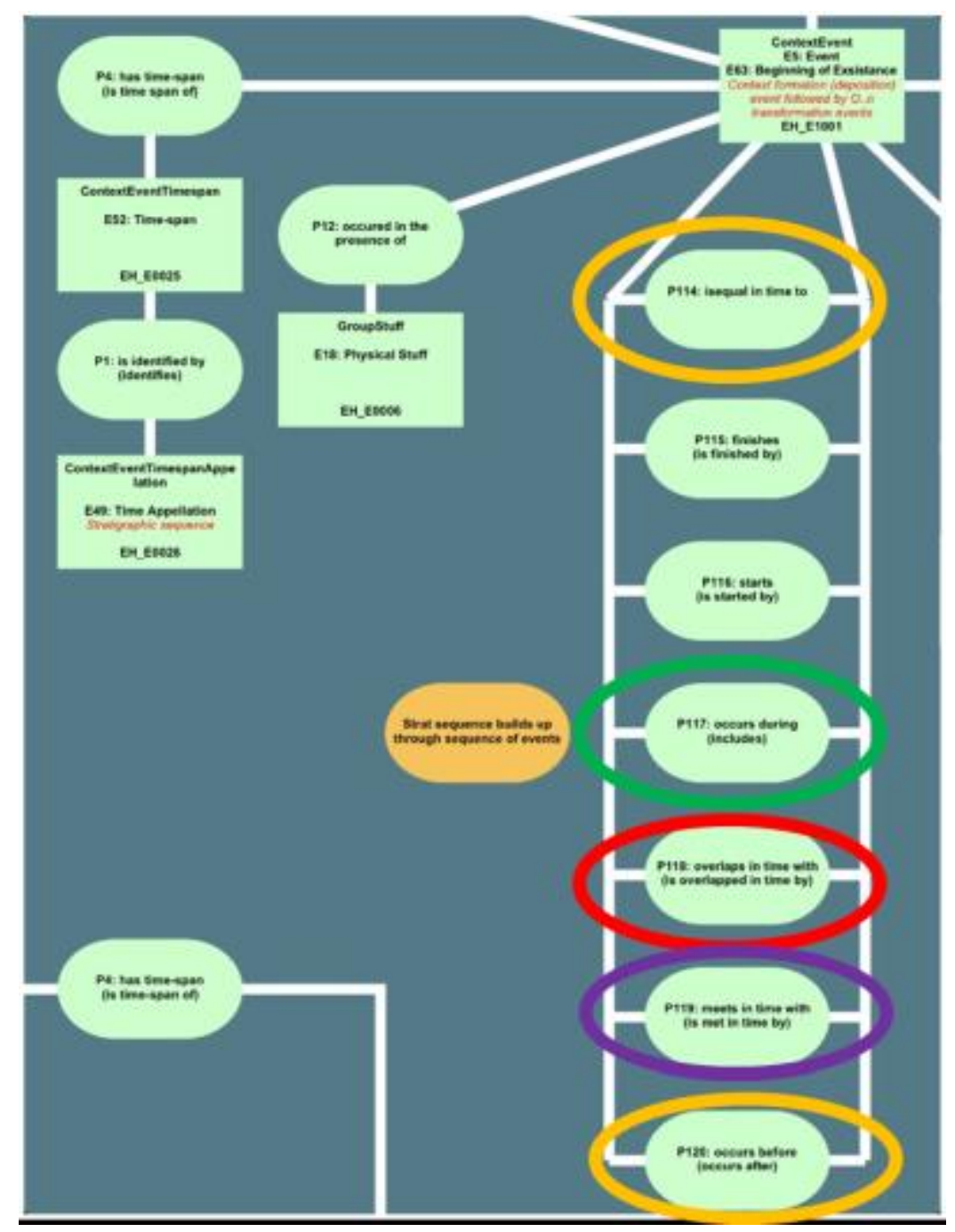

Figure 9: Allen operators as CIDOC-CRM properties with allocated 'P' numbers. $P 120$ : occurs before (occurs after) P114: is equal in time to P115: finishes (is finished by) P116: starts (is started by) P117: occurs during (includes) P118: overlaps in time with (is overlapped in time by) P119: meets in time with (is met in time by)

The CRMarchaeo has built on this earlier work and has been extended to incorporate stratigraphic excavation data along with records derived from other recording methodologies across Europe. CRMarchaeo recognises that the stratigraphic relationship is implied by, and inferred from, the kind of physical relation identified between two stratigraphic units. CRMarchaeo identifies two types of stratigraphic units: 'Stratigraphic volume units', which are deposits, layers or other units of stratigraphy that are recorded as occupying physical space and 'Stratigraphic Interfaces' which, as Harris defined, includes the boundaries of the physical deposits along with the 'cut' (negative) interfaces that occur following the removal of existing strata, such as by digging a refuse pit or other 'holes' made through other physical stratigraphic units (Figure 10).

One major advantage of using an ontological modelling approach is that differently labelled data can be mapped to the general concept in the ontology, as long as the overall semantic description (scope note) is agreed to match the nature of the data item. As the CRM-SIG describes it, the fundamental principle of formal ontologies is to be able to say if something is the same thing in two different references. Therefore a 'single 
context' in a UK system can be agreed to be the same concept as a 'Unita Stratigrafica' or 'US' in an Italian system (Ioppolo and Sartorio 1990) or the excavation 'Unit' in the Çatalhöyük recording system (Taylor 2016).

In the next section, I will explain how more explicit use of the temporal modelling, as identified in the CIDOC-CRM, can help make analysis data more interoperable. This, in turn, will lead to better standardised deposition of archaeological records. Better structuring and deposition of digital records of stratigraphic analysis would enable easier and more effective re-use of stratigraphic data for research purposes, such as Bayesian modelling methodologies, particularly in the realm of scientific dating of stratified items and deposits (see Section 9.1).

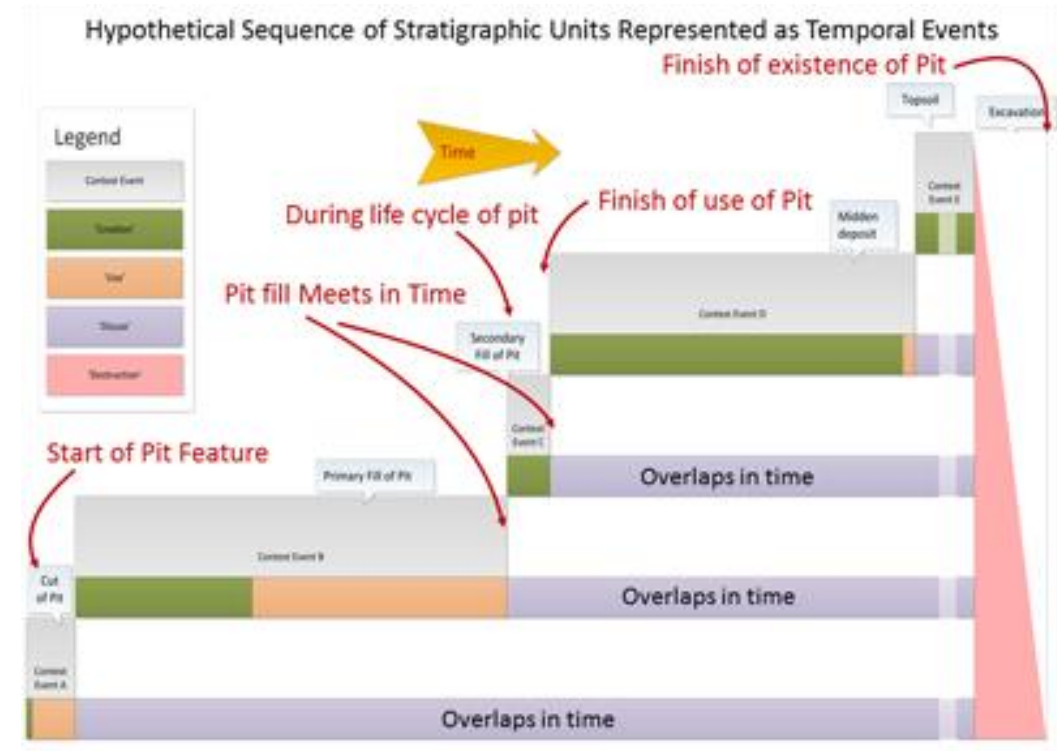

Figure 10: Diagram showing temporal relations in the continuity of hypothetical pit fills (based on an original version by Paul Cripps)

\section{Allen Temporal Relations Implicit in Stratigraphic Analysis}

In the phasing process, the individual stratigraphic units that are interpreted as associated with a common activity are assigned to groups within the same relative temporal phase. In practice, a number of levels of hierarchical grouping (sub-groups, blocks, land-uses, etc.) may be included within phases, depending upon the complexities of the stratigraphy concerned (Roskams 2001, 13.6). The various temporal relationships that can be expressed between these groups and phases are considered in turn below.

\subsection{Meets in time}

Phases are usually designed to be sequential, and they are generally assembled by the stratigraphic analyst to run in an unbroken sequence for the interpreted duration of the archaeological site. Most commonly, a numbering or lettering sequence, or some 
combination of both, is used (e.g. Phase 1, 2, 3, etc.). Most commonly in postexcavation analysis, archaeological phases are conceptually designed to be contiguous so that they meet in time with the preceding and succeeding phase in a phasing sequence. However, there may be circumstances in other analyses of the data, especially during chronological modelling, where phases could be designed to overlap or have gaps, as suggested by Buck et al. $(\underline{1996}, 218$, fig. 9.8). Recording this 'Meets in Time' relationship explicitly in the dataset where it is expressed in the phasing process (ideally in the database under the Phasing Index) would therefore be advantageous both for completeness of record and for those researchers attempting to revisit the data from the archive.

This Meets in Time relationship for phases is conceptually in contrast to the stratigraphic Before/After relationship. As we have noted, Harris' Law of Stratigraphic succession acknowledges that while stratigraphic units meet physically, that does not necessarily imply that they directly meet contiguously temporally. There will be a point in time in the past (the deposition event) when the two deposits came together spatio-temporally in sequence, but that is not the same as either spatial or temporal continuity.

\subsection{Starts/started by and Finishes/finished by}

Individual stratigraphic units will have a Before/After temporal relation, but there is usually a temporal Interface between the spatio-temporal Finish of the lower layer and the spatio-temporal Start of the layer above (which in most cases corresponds to the start of a separate temporal interval of indeterminate timespan). This is what Harris refers to as the 'Rope of Time' (see Figure 11 and discussion in Section 8.4).

\subsection{Occurs during}

If individual groups and their constituent stratigraphic units are assigned to the same relative temporal phase, then the implication is that those stratigraphic units or groups occur during the same phase of activity. Where phases are sub-divided by letters or subsidiary numbers (e.g. Phase $4 \mathrm{a}, 4 \mathrm{~b}, 4 \mathrm{c}$, etc.), then it recognises the temporal relationship sub-phase $4 \mathrm{~b}$ occurs during the overall Phase 4.

\subsection{Overlaps in time}

The grouping process is not just about sequencing but supports the interpretation that each context in the group was generated as, or was part of, the same activity and therefore functioning together at roughly the same time as the other contexts in the same group. Contexts that are assigned to the same group are interpreted to be part of the same group activity, implying that those same contexts in that group must have existed concurrently and therefore contexts in the same group can be said to overlap in time with each other.

We can also relate otherwise separate 'strands' of the stratigraphic sequence, represented as separate strands on the matrix diagram, by recording which groups of stratigraphic units overlap in time with others. This is implicit in the matrix when a set of contexts are placed at broadly the same horizontal level as each other in the diagram. 
One question that arises from this is how the relationships may differ between temporal overlaps between contexts on the same strand of a stratigraphic sequence as opposed to overlaps between contexts on completely separate stratigraphic strands. In some circumstances with limited dating evidence, no clear temporal overlap (or other temporal relationship) will be discernible between separate strands of the matrix but I would argue that in the case where an overlapping temporal relation is identified, then it would be worth noting that such a relationship has been detected. This would be preferable to the current circumstance where any overlapping of contexts or groups across the matrix is often highly ambiguous or, where rough approximations of horizontal levelling are used to represent some undefined degree of temporal correlation or overlap.

\subsection{Interfaces considered in the light of Allen operators}

Interfaces, which I take here to mean separate surfaces of activity, are generally only explicitly recorded in fieldwork (i.e. given separate context numbers) when they clearly truncate other stratigraphic units. Most commonly these occur when cuts or holes have been made through other deposits (e.g. pit cuts and postholes which then fill up, or are deliberately filled, with other material, or new doorways and openings cut through standing walls). In single context recording, a cut gets recorded with its own context number and then it has physically sequenced relationships recorded to any contexts that fill it up or which it cuts through. But there are other interfaces between stratigraphic units that do not usually get given context numbers during excavation, often for pragmatic reasons to save time and resources in a tight excavation schedule, and where recording interfaces as separate units of stratigraphy would reduce the time for further excavating and recording more tangible archaeology (in some countries referred to as the 'positive' archaeology).

'Archaeological stratification is a matter of strata and interfaces, of deposition and nondeposition (or erosion). The periodization of stratigraphic sequences must have periods of deposition and periods of non-deposition. Put simply, at some times there will be activities on a site, from the digging of ditches, to the construction of buildings. At other times, the ground surface will simply be used for ordinary activities of life. Most archaeologists give only tacit acceptance to these interfacial periods' (Harris $\underline{1989}, 115)$.

In practice these interfaces (which Harris has described as 'missing' from the stratigraphic record) are recorded in single context plan drawings and phase plans and are thus re-creatable through the drawn and spatial record, now more commonly analysed using GIS. Such multi-context phase plans are most often the surfaces of activity between corresponding context layers that can be representative of passages of time when the upper interface of the layer remained as an open surface (e.g. a floor surface) prior to a further context being deposited on top of it.

Of course, archaeologists who use the Harris Matrix recognise the temporality of the unnumbered layer interfaces by drawing vertical lines of differing lengths in their diagrams to represent the Before/After (Allen) relationship and it is argued these are brought into the analysis at a later stage, when site-wide periods of activity are identified and correlated through the use of multi-context phase plans to illustrate the associated narrative text (Harris 1989, fig. 25). It is at this later analytic stage that the definition of a period boundary as an interface and its specification in the Harris Matrix as a correlation 
of interfaces and deposits is reconciled (Harris 1989, 67-68). But this may overlook the potential for temporal reasoning over such identifiable interfaces and any related inferred timespans that such surfaces of activity represent.

'Treating the layer interface as an integral part of the depositional context beneath it ignores the possibility that it represents a unit of time, either because the surface it represents was deflated by erosion, exposing old deposits, or because the surface itself was open for some time. The failure to record layer interfaces potentially introduces hiatuses into the chronological model' (Dye and Buck 2015, 85).

A more explicit recognition of stratigraphic interfaces could bridge, or better define, such temporal 'gaps' in the matrix. This would enable the better presentation of temporal continuity over the stratigraphic sequence, but also could allow us to introduce timespans (and for Bayesian purposes, relative dating) for known interfaces, temporal intervals between interfaces, and, perhaps attempt to add more accurate parameters to what Harris (1979) identifies as different 'ropes of time' in the stratigraphic sequences.

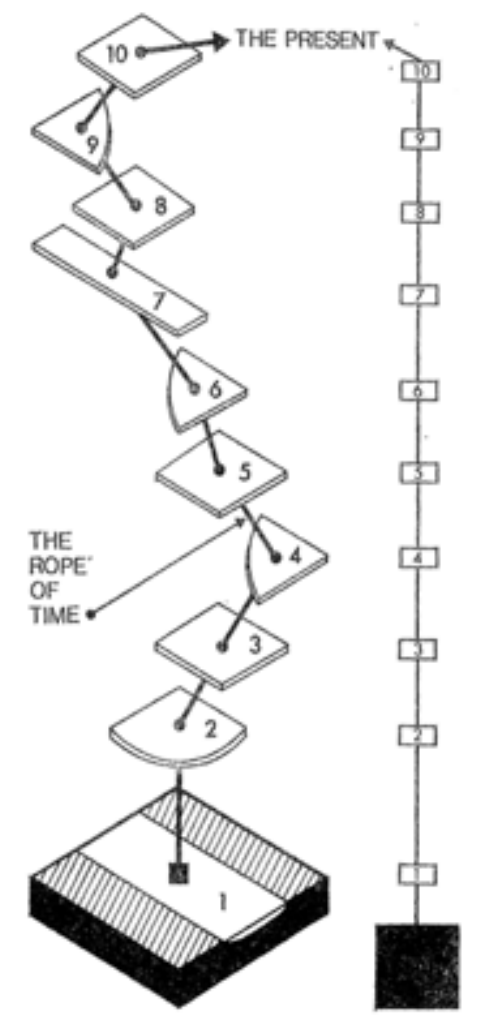

Figure 11: 'The Rope of time' (After Harris $\underline{1979}$, fig. 2)

\section{Use Cases for Incorporating Temporal Relationships in Stratigraphic Records}


There are a number of potential uses for more explicitly recorded temporal relationships as part of the stratigraphic records of an archaeological site. It seems clear that many of these temporal relationships are already being recognised or deduced during stratigraphic analysis, but they are not necessarily recorded in the same systematic way that the excavation process records the fundamental relationships of stratigraphically Before/After through a matrix diagram (and some versions of database records). This is most often for the practical reason that the stratigraphic relationships need to be recorded as part of the systematic record during the excavation of a site. The need to define the temporal relationships between sub-groups, groups, phases, landuses and periods is more often carried out after excavation is completed, by the individual(s) attempting to 'write-up' the site or prepare records during the analysis process that will lead to a publication. The information is more often written into publication texts, but much less often documented in the related database records.

I would emphasise the increasing need to archive these records in the best manner to enable digital cross-referencing of the finds and specialist data inherent to those analysis processes. This would also facilitate re-use of the data and identify relationships in the records, particularly for interoperability of data across different sites with related temporal phasing.

In addition, as the availability of digital archaeological data for re-use grows and as data analysis techniques have become more advanced, more systematic and standardised approaches to presenting the stratigraphic records of the post-excavation phasing process would greatly aid in the application of techniques such as Bayesian chronological modelling methods to archaeological data.

'At present, it appears to be the case that no archaeologists build their chronological models using formal algorithms. Instead they apply their expert judgment, selecting features from the stratigraphic record to include in the model on whatever basis they choose and justify their decisions in prose in the resulting publication. Such an approach may well lead archaeologists to learn all they wish to from the chronological evidence available, but it would be hard to demonstrate that and few authors at present even discuss the impact of their choice of chronological model on the results obtained' (Dye and Buck 2015, 90).

There seems definite potential and a use case for the development of a computerised Grouping and Phasing tool, able to use stratigraphic inputs, that would be designed to aid the stratigraphic analysis process (re-analysis) and enable a more standardised approach to the digital publication and archiving of stratigraphic analysis outputs. Further work as part of the recently AHRC funded 'The Matrix' project will address some of these research questions, but what this article will next consider is the kind of requirements that Bayesian modelling might have for more explicit temporal relationships in the archaeological records.

\subsection{Bayesian chronological modelling use of archaeological temporal sequences}

One difference between a Bayesian chronological model and an archaeological sequence diagram is that the Bayesian chronological model may include temporal relationships that cannot be expressed by just using the 
stratigraphic Before/After/Equals as defined by the Harris matrix (Buck et al. 1986, 218, fig. 9.8). Figure 12 recognises three possible relationships between two chronological phases where one is older than the other (Figure 7) yet 'Only two of these relationships can be represented stratigraphically' Dye and Buck (
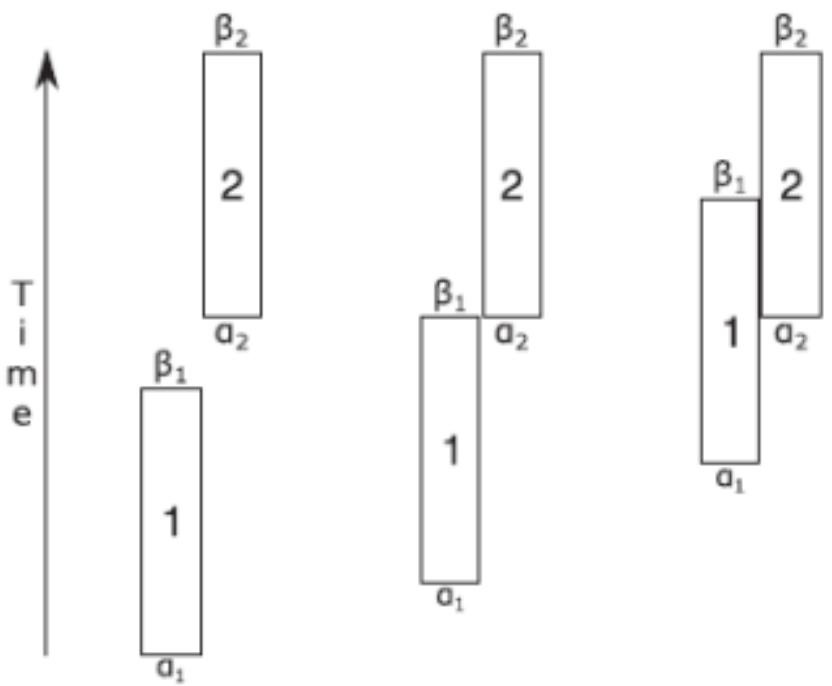

Figure 12: Schematic representation of three possible relationships between older and younger chronological phases: (left) chronological phases 1 and 2 separated, b1 > a2; (middle) chronological phases 1 and 2 abutting, b1 meets a2; (right) chronological phases 1 and 2 overlapping, b1 < a2. (After Dye and Buck 2015, fig.7, and adapted from Buck et al. 1996, fig. 9.8).

The relationships illustrated here are the Allen operators Before/After, Meets/Met in Time, Overlaps/Overlapped by in Time and the argument is made for more explicit recognition of the stratigraphic interfaces in archaeological records. Dye and Buck (2015) have proposed a Directed Acyclic Graph (DAG) methodology to explicitly represent where interfaces (referring directly back to Harris) can be represented as part of the stratigraphic record and enabling more accurate Bayesian models to be developed that take into account dating evidence derived from the interfaces in stratigraphic records.

'Given a directed graph of a hiatus-free archaeological sequence from which transitive relationships have been removed, it is possible to construct a Bayesian chronological model by combining the relative chronological information in the directed graph of the archaeological sequence diagram with the potentially dated events' (Dye and Buck 2015, 88).

The importance of the methodologies used for documentation by archaeologists of events representing changes in spatial and temporal relationships has been highlighted by other chronological modellers too:

'probably the most important interface between archaeology and the mathematical approaches taken in chronology building is the way in which we group and relate different events to one another. The groups that we chose to define are a product of our understanding of the human activity reflected in the archaeological record. The way we 
relate our events also usually depends critically on our interpretation of site stratigraphy and sample taphonomy' (Bronk-Ramsey 2015, 273).

\subsection{Stratigraphy in digital archive contents}

Current practice for archiving stratigraphic data from excavations is very variable and can, to a degree, reflect the scale and significance of the archaeological material found during an investigation. There is, however, no commonly accepted standard for digital archiving of stratigraphic data, although there are initiatives currently being undertaken to address some of the circumstances that lead to this issue, such as the 'Work Digital, Think Archive' project and the SEADDA project.

In many cases the stratigraphic matrices may only be archived as diagrams in a visual format (e.g. PDF of the diagram). This makes re-use of the stratigraphic relationships between the contexts much harder, if not impractical, if it involves re-entering stratigraphic data for all the matrix relationships that are represented as lines and boxes on a matrix diagram preserved only as an image.

In some cases, stratigraphic relationships may be recorded as separate columns in spreadsheets and archived in CSV format, which is substantially better for preservation and re-use purposes. In other cases, the stratigraphic relationships (or less commonly, the related phasing indices) will be held as part of the site database and will then be archived in a format that allows digital preservation and migration. Even so, and in either case, that does not necessarily guarantee commonality in how the stratigraphic information within the data are represented and preserved.

With the growing use of digital repositories for archaeological data, it is time for an international convention on stratigraphic records to make this fundamental archaeological data more useful and accessible to researchers, public sponsors and, not least, other archaeological practitioners who might make best use of such data in future archaeological investigations that need to compare data.

\section{Conclusions and Challenges}

The Harris matrix provides a successful, tried and tested methodology for archaeologists carrying out fieldwork, often where pressure of time on site requires a most succinct means of recoding stratigraphic relationships. The value of this method is not underestimated when identifying and documenting the stratigraphic sequence - the primary record made in the field is paramount. But in subsequent stages of the archaeological process such as stratigraphic analysis, when archaeologists need to introduce further methods for grouping and phasing of the identified stratigraphy, we may need to represent more complex temporal relations than just the fundamental sequence of stratigraphic relationships.

Consideration of more explicit ways of expressing temporal and spatio-temporal relations within archaeological records is needed. Ideally, the processes of grouping and phasing would also benefit from new ways to visualise the complexity of the temporal and spatio-temporal relations, thereby extending and improving the use of Harris matrix diagrams for stratigraphic analysis while maintaining links to the data for those relationships held in the site database records. Representing the granularity of the 
various temporal relationships, including spatio-temporal stratigraphic relationships, along with other Allen relationships within such analysis tools, would also help in conceptualising and explicitly sharing greater understanding of the temporal relationships that are currently only implicitly recorded in our records. I suggest that a more standardised approach to using the Allen temporal operators for representing the temporal relationships that are interpreted in the process of stratigraphic analysis would go some way to providing the 'intellectual clarity in defining concepts and then labelling them' that Roskams (2001) has previously called for.

This article has also sought to demonstrate why there is a need for more consistent standards in digital records of stratigraphic relationships, so that matrix data can be reused effectively e.g. as CSV files, rather than as images of matrix diagrams in a PDF document. There may also be a need for an international convention on stratigraphic recording and documentation to make this fundamental archaeological data more effectively Findable, Accessible, Interoperable and Re-usable (Force11 2016) across present day geo-political, and spatio-temporal, boundaries.

\section{Acknowledgements}

Particular thanks go to Edward Harris for his permission to use various illustrative figures in this article that are directly taken from the online copies of his publications made openly available online at http://harrismatrix.com/. Thanks also to Steve Roskams and James Taylor at University of York for numerous useful discussions and especially the collaboration on a joint presentation given at CAA2019 conference in Krakow that helped update some topics covered here.

Special thanks go to Caitlin Buck, Tom Dye and Bryony Moody for their most recent help in progressing both this article and on-going work related to The Matrix project. The Matrix project is funded by the Arts and Humanities Research Council [grant number $\mathrm{AH} / \mathrm{T} 002093 / 1$ ]. Particular thanks to Tom who was kind enough to read and give detailed comments on a draft of this article and who continues to engage with my stratigraphic discussions, often at relatively unsociable hours of the day because of the 11 hour time zone difference between the UK and Hawaii where he is based.

\section{Bibliography}

Allen, J.F. 1983 'Maintaining knowledge about temporal intervals', Communications of the ACM 26(11), November 1983. 832-43. https://doi.org/10.1145/182.358434

Barceló, J. and Bogdanovic, I. (eds) 2015 Mathematics in Archaeology, Boca Raton: Taylor and Francis. https://doi.org/10.1201/b18530

Bronk Ramsey, C. 2015 'Bayesian Approaches to the Building of Archaeological Chronologies' in J. Barceló and I. Bogdanovic (eds) Mathematics in Archaeology, Boca Raton: Taylor and Francis. 272-292. https://doi.org/10.1201/b18530 
Carver, M. 2009 Archaeological Investigation, Abingdon: Routledge.

Clark, P. 2000a 'Negative features and interfaces' in S. Roskams (ed) Interpreting Stratigraphy, British Archaeological Reports Int. Ser. 910, Oxford: Archaeopress. 103-5.

Clark, P. 2000b 'Post-excavation analysis: moving from the context to the phase' in S. Roskams (ed) Interpreting Stratigraphy, British Archaeological Reports Int. Ser. 910, Oxford: Archaeopress. 157-59.

Cripps, P., Greenhalgh, A., Fellows, D., May, K. and Robinson, D-E. 2004 'Ontological modelling of the work of the Centre for Archaeology', CIDOC CRM Technical Paper. [PDF] http://old.cidoccrm.org/docs/Ontological Modelling Project Report \%20Sep2004.pdf and The CRMEH Diagram, [PDF] http://old.cidoc-crm.org/docs/AppendixA DiagramV9.pdf

Doerr, M., Stiff, Nm, Crofts, N., Stead, S. and Gill. T. 2011 CIDOC CRM, http://www.cidoc-crm.org/get-last-official-release

Doerr, M., Felicetti, A., Hermon, S., Hiebel, G., Kritsotaki, A., Masur, A., May, K., Ronzino, P., Schmidle, W., Theodoridou, M., Tsiafaki, D., Christaki, E.

2018 CRMarchaeo Excavation Model v1.4.4. http://www.cidoccrm.org/crmarchaeo/sites/default/files/CRMarchaeo v1.4.4.pdf

Dye, T.S. and Buck, C.E. 2015 'Archaeological sequence diagrams and Bayesian chronological models', Journal of Archaeological Science 63, 84-

93. https://doi.org/10.1016/j.jas.2015.08.008

English Heritage 2014 Silbury Hill archive [data-set], York: Archaeology Data Service [distributor] https://doi.org/10.5284/1024570

Force 112016 FAIR Data Principles [Last accessed: 28 May 2020] https://www.force11.org/group/fairgroup/fairprinciples

Harris, E. 1979 'The laws of archaeological stratigraphy', World Archaeology 11(1), 11117. https://doi.org/10.1080/00438243.1979.9979753

Harris, E. 1989 Principles of Archaeological Stratigraphy, 2nd Edition, London and New York: Academic Press. https://doi.org/10.1016/C2009-0-21688-6

Harris, E., Brown, M. and Brown, G. (eds) 1993 Practices of Archaeological Stratigraphy, London: Academic Press Ltd.

Historic England (was English Heritage)2006 Recording Manual, Internal publication.

Ioppolo, G. and Sartorio, G.P. 1990 Lo Scavo Archaeologico, Commune di Roma, Assessorato alla Cultura.

Lucas, G. 2005 The Archaeology of Time, London:

Routledge. https://doi.org/10.4324/9780203004920 
Niccolucci, F. and Herman, S. 2015 'The formal logical foundations of archaeological ontologies' in J.A. Barceló and I. Bogdanovic (eds) Mathematics in Archaeology, Boca Raton: Taylor and Francis. 257-271. https://doi.org/10.1201/b18530

Powlesland, D. and May, K. 2010 'DigIT: Archaeological summary report and experiments in digital recording in the field', Internet Archaeology 27. https://doi.org/10.11141/ia.27.2

Roskams, S. (ed) 2000 Interpreting Stratigraphy. Papers presented to the Interpreting Stratigraphy Conferences 1993-1997, British Archaeological Reports Int. Ser. 910, Oxford: Archaeopress.

Roskams, S. 2001 Excavation, Cambridge: Cambridge University Press.

Shepherd, L. 1993 'Interpreting landscapes - analysis of excavations in and around the southern bailey of Norwich Castle' in J. Barber (ed) Interpreting Stratigraphy, Edinburgh: AOC (Scotland) Ltd. 3-10.

Spence, C. (ed) 1990 Archaeological Site Manual, 2nd Edition, London: The Museum of London.

Taylor, J.S. 2016 Making Time For Space At Çatalhöyük: GIS as a tool for exploring intra-site spatiotemporality within complex stratigraphic sequences, Unpublished PhD thesis, University of York. http://etheses.whiterose.ac.uk/13500/

Tudhope, D., May, K., Binding, C. and Vlachidis, A. 2011 'Connecting archaeological data and grey literature via semantic cross search', Internet Archaeology 30. https://doi.org/10.11141/ia.30.5

Vandevelde, S., Brochier, J.É., Desachy, B., Petit, C., and Slimak, L. 2018 'Sooted concretions: A new micro-chronological tool for high temporal resolution archaeology', Quaternary International 474, Part B, 103-

118. https://doi.org/10.1016/j.quaint.2017.10.031 